\title{
Home and neighbourhood correlates of BMI among children living in socioeconomically disadvantaged neighbourhoods
}

\author{
David A. Crawford ${ }^{1}$, Kylie Ball ${ }^{1}$, Verity J. Cleland ${ }^{1,2}$, Karen J. Campbell ${ }^{1}$, Anna F. Timperio ${ }^{1 *}$, \\ Gavin Abbott ${ }^{1}$, Johannes Brug ${ }^{3}$, Louise A. Baur ${ }^{4}$ and Jo A. Salmon ${ }^{1}$ \\ ${ }^{1}$ Centre for Physical Activity and Nutrition Research, School of Exercise and Nutrition Sciences, Deakin University, \\ 221 Burwood Highway, Burwood, VIC 3125, Australia \\ ${ }^{2}$ Menzies Research Centre, University of Tasmania, Private Bag 23, Hobart 7000, TAS, Australia \\ ${ }^{3}$ EMGO Institute for Health and Care Research, VU University Medical Center, Van der Boechorststraat 7, 1081 BT \\ Amsterdam, The Netherlands \\ ${ }^{4}$ Discipline of Paediatrics and Child Health, University of Sydney, c/-Clinical School, The Children's Hospital at Westmead, \\ Locked Bag 4001, Westmead, NSW 2145, Australia
}

(Submitted 14 November 2010 - Final revision received 7 June 2011 - Accepted 15 June 2011 - First published online 9 August 2011)

\begin{abstract}
A detailed understanding of the underlying drivers of obesity-risk behaviours is needed to inform prevention initiatives, particularly for individuals of low socioeconomic position who are at increased risk of unhealthy weight gain. However, few studies have concurrently considered factors in the home and local neighbourhood environments, and little research has examined determinants among children from low socioeconomic backgrounds. The present study examined home, social and neighbourhood correlates of BMI $\left(\mathrm{kg} / \mathrm{m}^{2}\right)$ in children living in disadvantaged neighbourhoods. Cross-sectional data were collected from 491 women with children aged 5-12 years living in forty urban and forty rural socioeconomically disadvantaged areas (suburbs) of Victoria, Australia in 2007 and 2008. Mothers completed questionnaires about the home environment (maternal efficacy, perceived importance/beliefs, rewards, rules and access to equipment), social norms and perceived neighbourhood environment in relation to physical activity, healthy eating and sedentary behaviour. Children's height and weight were measured at school or home. Linear regression analyses controlled for child sex and age. In multivariable analyses, children whose mothers had higher efficacy for them doing physical activity tended to have lower BMI $z$ scores (B $=-0 \cdot 04,95 \%$ CI $-0 \cdot 06,-0 \cdot 02)$, and children who had a television (TV) in their bedroom (B = 0.24, $95 \%$ CI 0.04, 0.44) and whose mothers made greater use of food as a reward for good behaviour $(\mathrm{B}=0 \cdot 05,95 \%$ CI $0 \cdot 01,0 \cdot 09)$ tended to have higher BMI $z$ scores. Increasing efficacy among mothers to promote physical activity, limiting use of food as a reward and not placing TV in children's bedrooms may be important targets for future obesity prevention initiatives in disadvantaged communities.
\end{abstract}

\section{Key words: BMI: Family environment: Neighbourhood environment}

Obesity poses one of the most challenging public health problems of the 21st century. Although we have a good understanding of the behavioural aetiology of obesity (energy imbalance due to poor eating and/or inadequate physical activity), the underlying drivers of these obesity-risk behaviours are yet to be elucidated. Given that as many as one in four children in developed countries are overweight or obese, that childhood obesity makes an impact on immediate and long-term health and that the prevalence of childhood obesity has doubled in the past 20 years, gaining an understanding of the drivers of obesity-risk behaviours is crucial. This is particularly so for those who are socioeconomically disadvantaged, who are more likely to eat poorly, to be physically inactive and to be overweight or obese ${ }^{(1)}$. Social-ecological theory posits that a range of personal, social and environmental level factors influence health behaviours ${ }^{(2)}$. Emerging evidence suggests that factors in the home and local neighbourhood environments may be important in determining weight status among children. Although these factors are believed to have an impact on obesity, there are relatively few empirical studies among children and the evidence is far from conclusive. Even fewer studies have considered the social environment.

In the home environment, more frequent dinner consumption while watching television (TV $)^{(3)}$, more frequent fast food

Abbreviation: TV, television.

*Corresponding author: Dr A. F. Timperio, fax +6139244 6017, email anna.timperio@deakin.edu.au 
consumption at home ${ }^{(3)}$, the number of opportunities to engage in screen-based behaviours (i.e. TV viewing, electronic games or computers) at home ${ }^{(4)}$ and having a TV in the bedroom ${ }^{(5)}$ are positively associated with BMI $z$ scores or weight status in children. Evidence relating parents' use of restriction in feeding to child weight is equivocal, with some studies showing no association with weight ${ }^{(6-8)}$, some showing it to be predictive of increased weight ${ }^{(9,10)}$ and others showing it to be protective against changes in weight ${ }^{(11,12)}$. In addition, parental modelling of physical activity ${ }^{(13)}$, sibling engagement in physical activity and the number of physical activity items at home are negatively associated with change in BMI $z$ scores in girls ${ }^{(4)}$.

There is a dearth of studies examining relationships between the social environment and adiposity in children. It is generally accepted that social influences on physical activity and nutrition become more pronounced with age. Some studies have shown positive relationships between social norms and physical activity among children and preadolescents $^{(14,15)}$, and social norms are consistent predictors of several eating behaviours in youth ${ }^{(16)}$. However, there are no studies that have examined associations between social norms for physical activity and eating behaviours and adiposity in children.

In terms of the local neighbourhood environment, inconsistent findings have been reported, with variation by sex, age and area of residence ${ }^{(17)}$. Parental perceptions of heavy traffic and concerns about traffic are positively associated with children's weight status ${ }^{(18)}$, but proxy objective measures (length of local and busy roads) were unrelated to adiposity in cross-sectional and longitudinal analyses ${ }^{(19)}$. The number of sport and recreation spaces was negatively associated with BMI $z$ scores in one study ${ }^{(19)}$, but most other studies have found no association between access to facilities or spaces for physical activity and obesity outcomes in children ${ }^{(17)}$. Walkability and street connectivity may also be important, with cross-sectional studies finding lower odds of overweight in pre-school girls living in walkable neighbourhoods and neighbourhoods with many intersections ${ }^{(20)}$ and lower BMI $z$ scores with increasing length of access paths (shortcuts) available in the neighbourhood ${ }^{(19)}$. Longitudinal analyses have found negative associations between number of fourway intersections and increase in BMI $z$ scores over 3 years $^{(19)}$. Very little work has focused on neighbourhood food environments among children. Most studies focus only on availability of fast food outlets, and these have found no associations between availability of fast food outlets and risk of overweight among children ${ }^{(21)}$. In a more comprehensive examination, although with a small sample, higher odds of having a high BMI were found for those with a convenience store in their census block, but no associations were found with restaurants, fast food restaurants, supermarkets, grocery stores or specialty stores ${ }^{(22)}$.

Although there has been some research examining the role of home and neighbourhood factors in relation to childhood obesity, few studies have concurrently considered factors associated with children's weight status in both the home and local neighbourhood environments ${ }^{(23)}$, and there has been little research that has examined determinants among children from low socioeconomic backgrounds or relationships with social norms. Given that public health efforts to date to curb the obesity epidemic have largely failed, gaining a more detailed understanding of the underlying drivers of obesity-risk behaviours is important in order to inform future prevention initiatives, particularly for individuals of low socioeconomic position who are at increased risk of unhealthy weight gain. The aim of this paper is to examine home, social and neighbourhood correlates of BMI in children living in disadvantaged neighbourhoods.

\section{Methods}

\section{Participants}

Data were collected during 2007-2008, as part of the Resilience for Eating and Activity Despite Inequality study. Ethical approval was granted by the Deakin University Human Research Ethics Committee, the Catholic Education Office and the Victorian Department of Education and Early Child Development.

In all, forty urban and forty rural socioeconomically disadvantaged areas (suburbs) of the state of Victoria were randomly selected. Areas were classified using the Australian Bureau of Statistics' 2001 Socio-Economic Index for Areas, an indicator of area-level disadvantage constructed from the population census ${ }^{(24)}$, and those areas within the bottom third of the Socio-Economic Index for Areas distribution for the state comprised the sampling frame.

A total of 150 women, aged 18-45 years, from each of the eighty areas were randomly identified from the Australian electoral roll ( $n$ 11940; in some areas in which there were fewer than 150 eligible women, all eligible women were sampled); 4934 women (41\%) responded to a postal invitation to complete a questionnaire. For privacy reasons, information on non-responders is not available from the Australian Electoral Commission. Data were excluded for 585 respondents wherein the respondent had moved from the sampled suburb before completing the survey ( $n$ 571), wherein the person who completed the survey was not the intended participant ( $n$ 3), wherein respondents withdrew their data after completing the survey ( $n$ 2) or wherein respondents were aged $<17$ or $>46$ years ( $n 9)$ ). Of the 4349 eligible women, those with a 5 - to 12 -year-old child ( $n$ 1457) were invited to complete an additional survey about their child (selected using the next-birthday method), with 771 (53\%) agreeing to do so. Child surveys were received from 613 mothers. More mothers who returned child surveys had a higher level of education $(25.7 v .17 .6 \% ; P<0.001)$ and were older $(38.5$ (SD 5.1) v. 37.1 (SD 6.3) years; $P<0 \cdot 001$ ) than mothers who were not mailed a survey or did not return a completed survey. There were no differences in marital status, number of children, BMI or weight status between these two groups.

\section{Measures}

Demographic information. The age of each child at the time their height and weight were measured was recorded, along 


\section{N British Journal of Nutrition}

Table 1. Measures used to assess home, social and neighbourhood environment characteristics among Resilience for Eating and Activity Despite Inequality children aged 5-12 years*

\section{Measures \\ Home environment \\ Maternal efficacy for child doing \\ physical activity (ten items)}

Survey items

Maternal self-efficacy for preventing child from engaging in sedentary behaviours (three items)

Maternal self-efficacy for child eating healthily (six items)

Parental support for physical activity (four items)

Importance of doing physical activity as a family (one item)
I think my child could be physically active: 'no matter how busy his/her day is', 'no matter how tired he/she may feel', 'even if it is hot or cold outside', 'even if he/she has a lot of homework', 'after school even if he/she could watch TV or play video games instead', 'even if he/she had to stay at home', 'even when he/she would rather be doing something else', 'even if his/her friends didn't want him/ her to', 'after school even if his/her friends wanted him/her to do something else', 'at least 3 times a week for the next 2 weeks' (38)

How confident are you that you could do the following over the next year? 'Say no to my child's demands to watch TV/videos/DVD', 'Say no to my child's requests to play on the computer', 'Get my child to do something physically active, like dancing, skipping, playing outside, when they want to play on the computer or watch TV

How confident are you that you could do the following over the next year? 'Get my child to eat enough fruit (this does not include fruit juice)', 'Get my child to eat enough vegetables (this does not include potato or potato chips)', 'Get my child to drink plain water (with no flavours added)', 'Say no to my child's requests for soft-drinks, cordials or other sweetened drinks', 'Say no to my child's requests for potato chips/Twisties/Cheezels or similar foods', 'Say no to my child's requests for sweet snacks, confectionary, lollies or ice-cream'

How often do the following people provide support for your child's participation in physical activity? (e.g. take him/her to training, provide money for participation, buy sports clothing/equipment): 'You', 'Child's co-carer' (these two scores were subsequently summed to indicate parental support) How often do each of the following people praise your child for participating in physical activity? (e.g. say positive things to him/her, seem happy that he/she does it): 'You', 'Child's co-carer' (these two scores were subsequently summed to indicat parental praise; parental support and parental praise scales were then summed to provide an indicator of overall parental support/praise, termed 'parental support for physical activity') ${ }^{(39)}$

How important is it (to you) that the family does sport or other physical activity together (e.g. goes for walks)?

Scale and range

Descriptives/scale reliability

Four point: $1=$ not at all confident, $4=$ very confident; range: $10-40$

Five point: $1=$ not at all confident, $5=$ extremely confident; range: $3-15$

Five point: $1=$ not at all confident, $5=$ extremely confident; range: $6-30$

$1=$ Don't know/doesn't apply, $2=$ never, $3=$ les than once/week, $4=1-2$ times/week, $5=3-4$ times/week, $6=5-6$ times/week, 7 = daily (subsequently recoded into times/week scores); range: $0-28$

$1=$ Not really important, $2=$ quite important $3=$ very important
Mean: 30.2 (SD 5.0): Cronbach's $\alpha=0.90$

Test-retest: $\kappa=0.46-0.64$

Mean: 11.5 (SD 2.8); $\alpha=0.82$ Test-retest: $\kappa=0.46-0.55$

Mean: 22.9 (SD 4.4); $\alpha=0.79$ Test-retest: $\kappa=0.47-0.61$

Mean: 12.3 (SD 6.6); $\alpha=0.74$ Test-retest: ICC $=0.81-0.90^{(4)}$

Distribution: 'not really important' (18.5\%), 'quite important' (46.8\%), 'very important' $(34.6 \%)$

Test-retest: $\kappa=0.64$ 
Measures (two items)

Sedentary behaviours as reward for good behaviour (two items)

Rules to limit sedentary behaviours (five items)

Feelings about food enjoyment (one item)

Beliefs about food enjoyment (one item)

Home access to physical activity equipment (eleven items)

Home access to equipment for sedentary behaviour (six items)

Child has TV in bedroom (one item)

\section{Social environment}

Social norms for physical activity

(three items)

Social norms for unhealthy eating (two items)

Social norms for eating fruit (one item)

\section{Survey items}

How much do you agree or disagree with the following: 'I offer sweets (e.g. lollies, ice cream, cake, pastries, sweet biscuits) to my child as a reward for good behaviour', 'I offer my child his/her favourite foods in exchange for good behaviour'(27)

How much do you agree or disagree with the

How much do you agree or disagree with the good behaviour', 'I let my child play computer/video games in exchange for good behaviour'(27)

'My child is not allowed to watch TV/play Playsta-

tion ${ }^{\odot} /$ Nintendo ${ }^{\odot}$ until his/her homework is done',

'During meal times, I do not allow the TV to be on',

'My child must be supervised when watching TV',

'My child must be supervised on the Internet or when playing Playstation ${ }^{\mathcal{O}} /$ Nintendo $^{\mathcal{O}}$, 'I limit the amount of time my child spends watching TV/using the computer (internet and games)'

How much do you agree or disagree with the following: 'It gives me pleasure to give my children food they enjoy'(27)

How much do you agree or disagree with the following: 'I believe in letting children enjoy food treats/rewards'(27)

Which of the following do you have outside of your home or in your yard? 'swimming pool/spa' 'trampoline', 'basketball ring'

Does your child have access to the following thing at home? 'balls', 'bats/racquets/golf clubs', 'bikes', 'home gym equipment', 'rollerblades', 'skateboard', 'skipping rope', 'scooter'

Does your child have access to the following things at home? 'free to air TV', 'pay TV', 'video/DVD player', 'Playstation $/$ Nintendo $\% /$ Gameboy $\%$ player', 'Playstation /Nintend,

Does your child have a TV in his/her bedroom?

How much do you agree or disagree with the following: 'Lots of kids we know play sport', 'Lots of kids we know walk or cycle to school', 'Lots of kids we know play outdoors'

How much do you agree or disagree with the How much do you agree or disagree with the
following: 'Lots of kids we know eat fast food often', 'Lots of kids we know drink soft drink often' How much do you agree or disagree with the following: 'At my child's school, lots of kids eat fruit often'
Scale and range

Descriptives/scale reliability

Five point: $1=$ strongly disagree, $5=$ strongly agree; range: $2-10$

Mean: 4.5 (SD 1.8); $\alpha=0.78$

Test-retest: $\kappa=0.50-0.55$

Five point: $1=$ strongly disagree, $5=$ strongly agree; range: $2-10$

Five point: $1=$ strongly disagree, $5=$ strongly agree; range 5-25

Five point: $1=$ strongly disagree, $5=$ strongly agree; range: $1-5$

Five point: $1=$ strongly disagree, $5=$ strongly agree; range: $1-5$

$0=$ No, $1=$ yes; range: $1-11$

$0=$ No, $1=$ yes; range: $0-6$

$0=$ No, $1=$ yes

Five point: $1=$ strongly disagree, $5=$ strongly agree; range: $3-15$

Five point: $1=$ strongly disagree, $5=$ strongly agree; range: $2-10$

Five point: 1 = strongly disagree, 5 = strongly agree; range: $1-5$
Mean: 4.5 (SD 1.9); $\alpha=0.86$ Test-retest: $\kappa=0.46-0.55$

Mean: 17.3 (SD 3.5); $\alpha=0.69$ Test-retest: items $1-4$, ICC $=0.77-$ $0.90^{(41)} ;$ item $5, \kappa=0.51$

Mean: 3.8 (SD 0.9)

Test-retest: $\kappa=0.47$

Mean: 3.4 (SD 0.9)

Test-retest: $\kappa=0.48$

Mean: $7 \cdot 7$ (SD 2.1)

Test-retest: $>89 \%$ agreement $^{(4)}$

Mean: 4.4 (SD 1.2)

Test-retest: $>91 \%$ agreement $^{(4)}$

Distribution: 'no' (74.7\%), 'yes' (25.3\%)

Test-retest: $>91 \%$ agreement $^{(40)}$

Mean: 11.5 (SD 1.8); $\alpha=0.57$

Test-retest: $62-73 \%$ agreement

Mean: 6.9 (SD 1.7); $\alpha=0.80$

Test-retest: $\kappa=0.53-0.57$

Mean: 3.8 (SD 0.8 )

Test-retest: $\kappa=0.51$ 


\begin{tabular}{|c|c|c|c|}
\hline Measures & Survey items & Scale and range & Descriptives/scale reliability \\
\hline \multicolumn{4}{|l|}{ Neighbourhood environment } \\
\hline $\begin{array}{l}\text { Mothers' perception of neighbourhood } \\
\text { physical activity environment (one } \\
\text { item) }\end{array}$ & $\begin{array}{l}\text { How much do you agree or disagree with the } \\
\text { following: 'The neighbourhood I live in has lots of } \\
\text { good places for my child to play and be active'(41) }\end{array}$ & $\begin{array}{l}\text { Five point: } 1=\text { strongly disagree, } 5=\text { strongly agree; } \\
\text { range: } 1-5\end{array}$ & $\begin{array}{l}\text { Mean: } 3.6(\mathrm{SD} 1.0) \\
\text { Test-retest: } \kappa=0.54\end{array}$ \\
\hline $\begin{array}{l}\text { Neighbourhood child friendliness/ } \\
\text { knowledge/liking (two items) }\end{array}$ & $\begin{array}{l}\text { How much do you agree or disagree with the } \\
\text { following: 'My child knows our local area very } \\
\text { well', 'My child likes living in our local area' }\end{array}$ & $\begin{array}{l}\text { Five point: } 1=\text { strongly disagree, } 5=\text { strongly agree; } \\
\text { range: } 2-10\end{array}$ & $\begin{array}{l}\text { Mean: } 8.2(\mathrm{SD} 1.4) ; \alpha=0.60 \\
\text { Test-retest: } 73-80 \% \text { agreement }\end{array}$ \\
\hline $\begin{array}{l}\text { Neighbourhood social network (three } \\
\text { items) }\end{array}$ & $\begin{array}{l}\text { How much do you agree or disagree with the } \\
\text { following: 'My child often visits other children and } \\
\text { families in my area', 'My child's friends live too far } \\
\text { away from home to see on a regular basis', 'There } \\
\text { are not many other children nearby for my child to } \\
\text { play or hang around with' }\end{array}$ & $\begin{array}{l}\text { Five point: } 1=\text { strongly disagree, } 5=\text { strongly agree } \\
\text { (the latter two items were reverse coded); range: } \\
3-15\end{array}$ & $\begin{array}{l}\text { Mean: } 10.9(\mathrm{SD} 2.6) ; \alpha=0.76 \\
\text { Test-retest: } 58-78 \% \text { agreement }\end{array}$ \\
\hline $\begin{array}{l}\text { Neighbourhood personal safety (four } \\
\text { items) }\end{array}$ & $\begin{array}{l}\text { How much do you agree or disagree with the } \\
\text { following statements about your local } \\
\text { neighbourhood: 'My neighbourhood is safe for } \\
\text { children', 'My neighbourhood is safe for my child to } \\
\text { walk/cycle around in the daytime', 'My child would } \\
\text { be safe walking home from a bus or train stop', } \\
\text { 'Concerns about stranger danger prevent my child } \\
\text { from going outside in my local area' }\end{array}$ & $\begin{array}{l}\text { Five point: } 1=\text { strongly disagree, } 5=\text { strongly agree } \\
\text { (the latter item was reverse coded); range: } 4-20\end{array}$ & $\begin{array}{l}\text { Mean: } 13.6 \text { (SD 3.2); } \alpha=0.80 \\
\text { Test-retest: } 51-77 \% \text { agreement }\end{array}$ \\
\hline $\begin{array}{l}\text { Neighbourhood road safety (four } \\
\text { items) }\end{array}$ & $\begin{array}{l}\text { How much do you agree or disagree with the } \\
\text { following statements about your local } \\
\text { neighbourhood: 'There are major barriers to } \\
\text { walking/cycling that make it hard for my child to get } \\
\text { from place to place (e.g. freeways, major roads)', } \\
\text { 'There are no lights/crossings/pedestrian over- } \\
\text { passes for my child to use', 'My child would have } \\
\text { to cross several roads to get to areas where } \\
\text { he/she can play or hang out', 'My child would have } \\
\text { to cross a busy road/major highway to get to areas } \\
\text { where he/she can play or hang out' }\end{array}$ & $\begin{array}{l}\text { Five point: } 1=\text { strongly disagree, } 5=\text { strongly agree } \\
\quad(\text { all items reverse coded); range: } 4-20\end{array}$ & $\begin{array}{l}\text { Mean: } 12.4(\mathrm{SD} \mathrm{3.5);} \alpha=0.79 \\
\text { Test-retest: } \kappa=0.53-0.59\end{array}$ \\
\hline $\begin{array}{l}\text { Neighbourhood availability and quality } \\
\text { of healthy foods (three items) }\end{array}$ & $\begin{array}{l}\text { How much do you agree or disagree with the } \\
\text { following: 'A large selection of fruit and vegetables } \\
\text { are available in my neighbourhood', 'The fresh fruit } \\
\text { and vegetables in my neighbourhood are of high } \\
\text { quality', 'A large selection of low-fat products are } \\
\text { available in my neighbourhood' }\end{array}$ & $\begin{array}{l}\text { Five point: } 1=\text { strongly disagree, } 5=\text { strongly agree; } \\
\text { range: } 3-15\end{array}$ & $\begin{array}{l}\text { Mean: } 11.2(\mathrm{SD} 2.4) ; \alpha=0.83 \\
\text { Test-retest: } \kappa=0.65-0.71\end{array}$ \\
\hline
\end{tabular}

TV, television; DVD, digital video disc; ICC, intra-class correlation coefficient.

* Children were recruited from socioeconomically disadvantaged suburbs in urban and rural areas of Victoria, Australia during 2007-2008. 
with their sex. Maternal age and education information was self-reported by mothers. Mothers reported the highest level of education that they had completed, with response categories: 'no formal education', 'year 10 or equivalent', 'year 12 or equivalent', 'trade/apprenticeship', 'certificate/diploma', 'university degree' and 'higher university degree'. Responses were collapsed into three categories of maternal education: low ('no formal education' or 'year 10 or equivalent'), medium ('year 12 or equivalent', 'trade/apprenticeship' or 'certificate/diploma') and high ('university degree' or 'higher university degree').

\section{Adiposity}

Research staff attended each child's school or home and measured height using a portable stadiometer and weight using digital scales. BMI was calculated for each child by dividing weight by height squared $\left(\mathrm{kg} / \mathrm{m}^{2}\right)$. Subsequently, age- and sex-adjusted BMI $z$ scores were calculated for each child based on the Centers for Disease Control reference population ${ }^{(25)}$. Additionally, child weight status (underweight, healthy weight, overweight or obese) was determined using cut points of Cole et al. ${ }^{(26)}$.

\section{Home environment}

Measures of the home environment were included in the survey completed by mothers (Table 1). These included measures of: maternal efficacy for the child doing physical activity; maternal efficacy for preventing the child engaging in screen-based behaviours; maternal efficacy for the child eating healthily; parental support for physical activity; maternal perception of the importance of doing physical activity as a family; views on the use of food as a reward; views on the use of screen-based behaviour as a reward; having rules to limit screen-based behaviours; feelings and beliefs about food enjoyment (measured with the items, 'it gives me pleasure to give my children the food they enjoy'; 'I believe in letting children enjoy foods treats/rewards'); home access to physical activity equipment; home access to opportunities for screen-based behaviours; and the children having access to a TV in their bedroom.

\section{Social environment}

Measures of social norms were included in the survey completed by mothers, including perceptions of: social norms for physical activity; social norms for unhealthy eating; and social norms for eating fruit (Table 1).

\section{Neighbourhood environment}

Measures of the neighbourhood environment were included in the survey completed by mothers. These included measures of perceptions of: the neighbourhood physical activity environment; neighbourhood familiarity; neighbourhood social network; neighbourhood personal safety; neighbourhood road safety; and neighbourhood availability and quality of healthy foods (Table 1).

\section{Statistical analysis}

Cronbach's $\alpha$ describing the internal reliability of measures (where appropriate) and $\kappa$ coefficients for 2-week testretest reliability of measures or previously published testretest reliability are provided (Table 1). Participants were excluded from analyses if they had missing data for BMI $z$ scores ( $n$ 50) or any of the correlates or covariates ( $n$ 122), leaving a final sample of $n$ 491. Associations between each correlate and BMI $z$ scores were examined via linear regression. Those variables that were significantly associated $(P<0.05)$ with BMI $z$ scores were then entered together into a multivariable linear regression model. All analyses were conducted controlling for two covariates, namely, child sex and child age. Owing to the clustered sampling procedure used, all analyses were controlled for clustering by suburb using STATA's 'cluster' command. STATA 10.1 (StataCorp, College Station, TX, USA) was used to perform all analyses.

\section{Results}

Demographic characteristics of the sample are presented in Table 2. The majority of the children (71.7\%) were in the healthy weight range. Approximately half of the children were male and had a mother with a medium level of education. The mean age of the children was 9.4 years and the mean age of their mothers was 38.8 years. A comparison of the 491 children whose data were included in the analysis sample and the 122 who were excluded because of missing data revealed no differences in children's BMI $z$ scores, weight status categories or maternal education. However, the children in the analytic sample were significantly older (mean age 9.5 v. 8.9 years) and had older mothers (mean age $38 \cdot 8 v .37 \cdot 1$ years).

Table 2. Sociodemographic characteristics of Resilience for Eating and Activity Despite Inequality study children and mothers*

(Mean values, standard deviations and percentages, $n$ 491)

\begin{tabular}{lcccc}
\hline Characteristic & $n$ & Mean & SD & $\%$ \\
\hline Child BMI z-score & 491 & 0.5 & 0.9 & \\
Child weight status & & & & \\
$\quad$ Healthy weight & 349 & & & $71 \cdot 1$ \\
$\quad$ Overweight & 96 & & & 19.6 \\
$\quad$ Obese & 46 & & 2.1 & \\
Child age & 491 & 9.4 & & \\
Child sex & & & & 47.0 \\
$\quad$ Male & 231 & & & 53.0 \\
$\quad$ Female & 260 & 38.8 & 4.9 & \\
Maternal age (years) & 491 & & & \\
Maternal education† & & & & 24.4 \\
$\quad$ Low & 119 & & & 26.4 \\
$\quad$ Medium & 240 & & \\
$\quad$ High & 129 & & \\
\hline
\end{tabular}

* Children were recruited from socioeconomically disadvantaged suburbs in urban and rural areas of Victoria, Australia during 2007-2008.

† The column total $n$ for this characteristic does not equal 491 due to missing data for three participants 
Partially adjusted and fully adjusted multivariable associations between exposure variables and BMI $z$ scores are presented in Table 3. Of the home environment characteristics, five were significantly associated with BMI $z$ scores in the individual regression analyses. Maternal efficacy for the child doing physical activity, preventing the child from engaging in screen-based behaviours and the child eating healthily were inversely associated with BMI $z$ scores, such that higher efficacy was associated with lower BMI $z$ scores. Additionally, using food as a reward for good behaviour was associated with higher BMI $z$ scores and children with a TV in their bedroom tended to have higher BMI $z$ scores than those without. Only one of the 'neighbourhood' characteristics was associated with BMI $z$ scores in the partially adjusted analyses. Greater agreement by mothers that their neighbourhood 'has lots of good places' for their child to play and be active was associated with lower BMI $z$ scores.

When the characteristics significantly associated with BMI $z$ scores in the individual analyses were entered into a multivariable model, only three remained significant. Children whose mothers had higher efficacy for them doing physical activity had significantly lower BMI $z$ scores, whereas children who had a TV in their bedroom and those whose mothers made greater use of food as a reward for good behaviour had significantly higher BMI $z$ scores.

\section{Discussion}

The present study sought to examine the home, social and local neighbourhood correlates of BMI $z$ scores in children living in disadvantaged communities. We found that a small number of potentially modifiable features of the home environment were associated with children's BMI $z$ scores, and that none of the social or neighbourhood factors were associated once the home environment was also considered. The findings suggest that increasing efficacy among mothers to promote physical activity, limit the use of food as a reward and not provide children with a TV in their bedroom are likely to be important targets for future obesity prevention initiatives in disadvantaged communities.

The finding that parental use of food as a reward is associated with increased BMI $z$ scores has not previously been described. This may reflect the fact that, until recently, the two items pertaining to use of food as a reward from Birch's Child Feeding Questionnaire ${ }^{(27)}$ have been included within the broader feeding restriction subscale. The present study

Table 3. Linear associations between home, social and neighbourhood environmental exposures and BMI $z$-score $\dagger$ (B coefficients and $95 \%$ confidence intervals, $n$ 491)

\begin{tabular}{|c|c|c|c|c|}
\hline \multirow[b]{2}{*}{ Exposures } & \multicolumn{2}{|c|}{$\begin{array}{c}\text { Partially adjusted } \\
\text { associations with BMI } \\
\text { z scores } \ddagger\end{array}$} & \multicolumn{2}{|c|}{$\begin{array}{c}\text { Multivariable (fully adjusted) } \\
\text { associations with } \\
\text { BMI } z \text { scores } \S\end{array}$} \\
\hline & $\mathrm{B}$ & $95 \% \mathrm{Cl}$ & B & $95 \% \mathrm{Cl}$ \\
\hline \multicolumn{5}{|l|}{ Home environment } \\
\hline Maternal efficacy for child doing physical activity & $-0.04^{\star \star \star}$ & $-0.06,-0.03$ & $-0.04^{\star \star *}$ & $-0.06,-0.02$ \\
\hline Maternal self-efficacy for preventing child from engaging in sedentary behaviours & $-0.04^{\star \star}$ & $-0.07,-0.01$ & 0.00 & $-0.04,0.04$ \\
\hline Maternal self-efficacy for child eating healthily & $-0.03^{\star \star \star}$ & $-0.05,-0.01$ & -0.01 & $-0.03,0.01$ \\
\hline Parental social support for physical activity & 0.00 & $-0.01,0.01$ & & \\
\hline \multicolumn{5}{|l|}{ Importance of doing physical activity as a family } \\
\hline \multicolumn{5}{|l|}{ Not really important (reference category) } \\
\hline Quite important & $0 \cdot 13$ & $-0.13,0.39$ & & \\
\hline Very important & 0.03 & $-0.26,0.31$ & & \\
\hline Food as reward for good behaviour & $0.06^{*}$ & $0.01,0.10$ & $0.05^{*}$ & $0.01,0.09$ \\
\hline Sedentary behaviours as reward for good behaviour & 0.02 & $-0.03,0.07$ & & \\
\hline Rules to limit sedentary behaviours & -0.02 & $-0.05,0.00$ & & \\
\hline 'It gives me pleasure to give my children food they enjoy' & 0.00 & $-0.09,0.09$ & & \\
\hline 'I believe in letting children enjoy food treats/rewards' & 0.06 & $-0.04,0.16$ & & \\
\hline Home access to physical activity equipment & -0.03 & $-0.06,0.00$ & & \\
\hline Home access to equipment for sedentary behaviours & 0.05 & $-0.03,0.13$ & & \\
\hline Child has TV in his/her bedroom & $0 \cdot 27^{\star \star}$ & $0.07,0.47$ & $0 \cdot 24^{*}$ & $0.04,0.44$ \\
\hline \multicolumn{5}{|l|}{ Social environment } \\
\hline Social norms for physical activity & -0.03 & $-0.08,0.01$ & & \\
\hline Social norms for unhealthy eating & 0.02 & $-0.03,0.07$ & & \\
\hline Social norms for eating fruit & 0.00 & $-0.11,0.10$ & & \\
\hline \multicolumn{5}{|l|}{ Neighbourhood environment } \\
\hline Neighbourhood physical activity environment & -0.10 & $-0.19,-0.01^{*}$ & -0.06 & $-0.15,0.03$ \\
\hline Neighbourhood familiarity & -0.03 & $-0.10,0.04$ & & \\
\hline Neighbourhood social network & -0.01 & $-0.05,0.02$ & & \\
\hline Neighbourhood personal safety & 0.00 & $-0.02,0.03$ & & \\
\hline Neighbourhood road safety & -0.01 & $-0.03,0.02$ & & \\
\hline Neighbourhood availability and quality of healthy foods & 0.00 & $-0.05,0.04$ & & \\
\hline
\end{tabular}

TV, television

Values were significantly different: ${ }^{*} P<0.05,{ }^{\star \star} P<0.01,{ }^{\star \star \star} P<0.005$

† Children were recruited from socioeconomically disadvantaged suburbs in urban and rural areas of Victoria, Australia during $2007-2008$.

¥ Adjusted for child age and sex, and clustering by suburb.

$\S$ Adjusted for other predictors in multivariable model, child age and sex and clustering by suburb. 
considered food as a reward specifically, and exploratory factor analyses undertaken on the Child Feeding Questionnaire ${ }^{(28)}$ in Australian samples have indicated that this is appropriate. Although there are no reports of associations between the use of food as a reward and child weight, a small number of cross-sectional studies report direct associations between use of food as reward and obesity-promoting eating $^{(29-31)}$. It may be that the use of food as a reward increases a child's preference for that food and in turn its consumption $^{(32)}$. If parents provide energy-dense foods as rewards, this may increase risk of unhealthy weight gain.

We are unaware of any research that has examined parental efficacy regarding their ability to influence children's lifestyle behaviours and child's weight status. However, Adkins et $a l .{ }^{(33)}$ reported that parent's self-efficacy for supporting their daughters to be active was associated with girls' engagement in physical activity. Among preschoolers, maternal self-efficacy was positively associated with water, fruit and vegetable consumption and was inversely associated with cordial and cake consumption ${ }^{(34)}$. In the same study, maternal self-efficacy to limit TV viewing time was inversely associated with screen time. The findings of the present study suggest that interventions that include a focus on improving mothers' confidence to influence children's obesity-risk behaviours may be important.

A small number of studies have reported positive associations between the presence of a TV in the bedroom and children's BMI $z$ scores or weight status ${ }^{(5,35)}$. A US expert panel reviewed the evidence of associations between children's TV viewing and weight, and with more than $60 \%$ of children over 8 years having a TV set in their bedroom, it recommended that parents remove TV from their child's bedroom or preferably not put them there in the first place ${ }^{(36)}$. A recent analysis of two large cross-sectional surveys (one from Germany, and the other from the USA) found that having a TV set in the bedroom mediated the association between socioeconomic status and BMI among 10- to 17-yearold children and adolescents in the two samples ${ }^{(37)}$. Given the focus of the present study on children and mothers living in socioeconomically disadvantaged neighbourhoods, this is an important consideration for families most at risk.

In contrast to previous studies ${ }^{(14-22)}$, none of the social or neighbourhood environmental factors remained significant in the multivariable analyses. In addition, relatively few of the home environment variables were significantly associated with BMI. These contrasting findings may be because previous studies have not considered a broad range of potential correlates across home, social and neighbourhood levels of influence simultaneously in the same model. The inclusion of a range of potential correlates in the home and neighbourhood environments, including the social environment, which is rarely considered, is an important strength of the present study. Other strengths include the objective measure of children's height and weight and the focus on an at-risk and under-served population group. Limitations of the present study include the cross-sectional study design, reliance on self-reported perceptions rather than objective measures of the neighbourhood environment and the use of maternal reports of other potential correlates.

\section{Conclusion}

The present study provides novel data on potentially modifiable influences on obesity among socioeconomically disadvantaged children that could underpin the development of initiatives aimed at preventing obesity. Developing strategies aimed at increasing mother's efficacy to promote physical activity, limit the use of food as a reward and disallow children to have a TV in their bedroom warrant further investigation as components of future obesity prevention programmes in disadvantaged communities.

\section{Acknowledgements}

The present study was funded by a National Health and Medical Research Council Strategic Award (ID 374241). D. A. C., K. J. C. and A. F. T. are supported by the Public Health Research Fellowships from VicHealth; K. B. (ID 479513) and V. J. C. (ID 533917) are supported by fellowships from the National Health and Medical Research Council; and J. A. S. is supported by a Fellowship from the National Heart Foundation of Australia and Sanofi-Aventis. D. A. C., K. B., A. F. T. and J. A. S. were involved in designing and conducting the study; V. J. C. was involved in coordinating the study; G. A. analysed the data; D. A. C., V. J. C., K. J. C. and A. F. T. wrote specific sections of the manuscript; and all authors contributed to drafting the manuscript, providing important intellectual contributions. All authors read and approved the final manuscript. The authors declare that there are no conflicts of interest.

\section{References}

1. Ball K \& Crawford D (2006) Socio-economic factors in obesity: a case of slim chance in a fat world? Asia Pac J Clin Nutr Suppl., 15, 15-20.

2. Stokols D (1996) Translating social ecological theory into guidelines for community health promotion. Am J Health Promot 10, 282-298.

3. MacFarlane A, Cleland V, Crawford D, et al. (2009) Longitudinal examination of the family food environment and weight status among children. Int J Pediatr Obes 4, 343-352.

4. Timperio A, Salmon J, Ball K, et al. (2008) Family physical activity and sedentary environments and weight change in children. Int J Pediatr Obes 3, 160-167.

5. Adachi-Mejia AM, Longacre MR, Gibson JJ, et al. (2007) Children with a TV in their bedroom at higher risk for being overweight. Int J Obes 31, 644-651.

6. Carnell S \& Wardle J (2007) Associations between multiple measures of parental feeding and children's adiposity in United Kingdom preschoolers. Obesity 15, 137-144.

7. Haycraft EL \& Blissett JM (2008) Maternal and paternal controlling feeding practices: reliability and relationships with BMI. Obesity 16, 1552-1558.

8. Powers SW, Chamberlin LA, van Schaick KB, et al. (2006) Maternal feeding strategies, child eating behaviors, and child BMI in low-income African-American preschoolers. Obesity 14, 2026-2033. 
9. Faith MS, Berkowitz RI, Stallings VA, et al. (2004) Parental feeding attitudes and styles and child body mass index: prospective analysis of a gene-environment interaction. Pediatrics 114, e429-e436.

10. Francis LA \& Birch LL (2005) Maternal weight status modulates the effects of restriction on daughters' eating and weight. Int J Obes 29, 942-949.

11. Campbell K, Andrianopoulos N, Hesketh K, et al. (2010) Parental use of restrictive feeding practices and child BMI $z$-score: a three year prospective cohort study. Appetite $\mathbf{5 5}$ $84-88$.

12. Farrow CV \& Blissett $\mathrm{J}$ (2008) Controlling feeding practices: cause or consequence of early child weight? Pediatrics 121, e164-e169.

13. Davison KK \& Birch LL (2002) Obesigenic families: parents' physical activity and dietary intake patterns predict girls' risk of overweight. Int J Obes 26, 1186-1193.

14. Sallis JF, Prochaska JJ \& Taylor WC (2000) A review of correlates of physical activity of children and adolescents. Med Sci Sports Exerc 32, 963-975.

15. Trost SG, Pate RR, Ward DS, et al. (1999) Correlates of objectively measured physical activity in preadolescent youth. $\mathrm{Am}$ J Prev Med 17, 120-126.

16. McClain AD, Chappuis C, Nguyen-Rodriguez ST, et al. (2009) Psychosocial correlates of eating behavior in children and adolescents: a review. Int J Behav Nutr Phys Act 12, 54.

17. Dunton GF, Kaplan J, Wolch J, et al. (2009) Physical environmental correlates of childhood obesity: a systematic review. Obes Rev 10, 393-402.

18. Timperio A, Salmon J, Telford A, et al. (2005) Perceptions of local neighbourhood environments and their relationship to childhood overweight and obesity. Int J Obes 29, 170-175.

19. Timperio A, Jeffery RW, Crawford D, et al. (2010) Neighbourhood physical activity environment and adiposity in children and mothers: a 3 year longitudinal study. Int J Behav Nutr Phys Act 7, 18.

20. Spence JC, Cutumisu N, Edwards J, et al. (2008) Influence of neighbourhood design and access to facilities on overweight among preschool children. Int J Pediatr Obes 3, 109-116.

21. Crawford DA, Timperio AF, Salmon JA, et al. (2008) Neighbourhood fast food outlets and obesity in children and adults: the CLAN Study. Int J Pediatr Obes 3, 249-256.

22. Galvez MP, Hong L, Choi E, et al. (2009) Childhood obesity and neighborhood food-store availability in an inner-city community. Acad Pediatr 9, 339-343.

23. Crawford D, Cleland V, Timperio A, et al. (2010) The longitudinal influence of home and neighbourhood environments on children's body mass index and physical activity over 5 years: the CLAN study. Int J Obes 34, 1177-1187.

24. Australian Bureau of Statistics (2003) Socio-economic Indexes for Areas, 2001. Canberra: Australian Bureau of Statistics.

25. Kuczmarski RJ, Ogden DL, Grummer-Strawn LM, et al. (2000) CDC Growth Charts: United States. Advance Data from Vital and Health Statistics: no. 314. Hyattsville, MD: National Center for Health Statistics.

26. Cole TJ, Bellizzi MC, Flegal KM, et al. (2000) Establishing a standard definition for child overweight and obesity worldwide: international survey. BMJ 320, 1240-1243.
27. Birch LL, Fisher JO, Grimm-Thomas K, et al. (2001) Confirmatory factor analysis of the Child Feeding Questionnaire: a measure of parental attitudes, beliefs and practices about child feeding and obesity proneness. Appetite 36, 201-210.

28. Corsini N (2008) Exploring Aspects of Parental Control Over Feeding: Influences on Children's Eating behaviour and weight. Adelaide: School of Psychology, University of Adelaide.

29. Kröller K \& Warschburger P (2009) Maternal feeding strategies and child's food intake: considering weight and demographic influences using structural equation modeling. Int $J$ Behav Nutr Phys Act 22, 78.

30. Spurrier NJ, Magarey AA, Golley R, et al. (2008) Relationships between the home environment and physical activity and dietary patterns of preschool children: a cross-sectional study. Int J Behav Nutr Phys Act 30, 31.

31. Vereecken C, Legiest E, De Bourdeaudhuij I, et al. (2009) Associations between general parenting styles and specific food-related parenting practices and children's food consumption. Am J Health Promot 23, 233-240.

32. Newman J \& Taylor A (1992) Effect of a means-end contingency on young children's food preferences. J Exper Child Psychol 53, 200-216.

33. Adkins S, Sherwood NE, Story M, et al. (2004) Physical activity among African-American girls: the role of parents and the home environment. Obes Res 12, 38S-45S.

34. Campbell K, Hesketh K, Silverii A, et al. (2010) Maternal self-efficacy regarding children's eating and sedentary behaviours in the early years: associations with children's food intake and sedentary behaviours. Int J Pediatr Obes, 5, 501-508.

35. Dennison BA, Erb TA \& Jenkins PL (2002) Television viewing and television in bedroom associated with overweight risk among low-income preschool children. Pediatr 109, $1028-1035$.

36. Jordan $\mathrm{AB}$ \& Robinson $\mathrm{TN}$ (2008) Children, television viewing, and weight status: summary and recommendations from an expert panel meeting. Ann Am Acad Polit Soc Sci 615, 119-132.

37. Morgenstern M, Sargent JD \& Hanewinkel R (2009) Relation between socioeconomic status and body mass index: evidence of an indirect path via television use. Arch Pediatr Adol Med 163, 731-738.

38. Saunders RP, Pate RR, Felton G, et al. (1997) Development of questionnaires to measure psychosocial influences on children's physical activity. Prev Med 26, 241-247.

39. Sallis JF, Grossman RM, Pinski RB, et al. (1987) The development of scales to measure social support for diet and exercise behaviors. Prev Med 16, 825-836.

40. Salmon J, Timperio A, Telford A, et al. (2005) Associations of family environment with children's television viewing and low level of physical activity. Obes Res 13, 1939-1951.

41. Rudestam K, Brown P, Zarcadoolas C, et al. (2004) Children's asthma experience and the importance of place. Health $\mathbf{8}$, 423-444. 